\title{
Absence of the MGMT protein as well as methylation of the MGMT promoter predict the sensitivity for temozolomide
}

\author{
KA van Nifterik ${ }^{*}$, , J van den Berg', WF van der Meide ${ }^{2}, \mathbf{N}$ Ameziane $^{3}$, LE Wedekind', RDM Steenbergen ${ }^{2}$, \\ S Leenstra ${ }^{4}$, MVM Lafleur', BJ Slotman', LJA Stalpers ${ }^{5}$ and P Sminia' \\ 'Department of Radiation Oncology, VU University Medical Center, P.O Box 7057, Amsterdam 1007 MB, The Netherlands; ${ }^{2}$ Department of Pathology, \\ VU University Medical Center, P.O Box 7057, Amsterdam 1007 MB, The Netherlands; ${ }^{3}$ Department of Clinical Genetics, VU University Medical Center, \\ P.O Box 7057, Amsterdam 1007 MB, The Netherlands; ${ }^{4}$ Department of Neurosurgery, St Elisabeth Ziekenhuis, Tilburg, The Netherlands; ${ }^{5}$ Department \\ of Radiotherapy, Academic Medical Center, Amsterdam, The Netherlands
}

BACKGROUND: The DNA repair protein $\mathrm{O}^{6}$-methylguanine-DNA methyltransferase (MGMT) can cause resistance to the alkylating drug temozolomide (TMZ). The purpose of this study was to determine the relationship between the MGMT status, determined by means of several techniques and methods, and the cytotoxic response to TMZ in I I glioblastoma multiforme (GBM) cell lines and 5 human tumour cell lines of other origins.

METHODS: Cell survival was analysed by clonogenic assay. The MGMT protein levels were assessed by western blot analysis. The MGMT promoter methylation levels were determined using methylation-specific multiplex ligation-dependent probe amplification (MS-MLPA) and quantitative real-time methylation-specific PCR (qMSP). On the basis of the results of these techniques, six GBM cell lines were selected and subjected to bisulphite sequencing.

RESULTS: The MGMT protein was detected in all TMZ-resistant cell lines, whereas no MGMT protein could be detected in cell lines that were TMZ sensitive. The MS-MLPA results were able to predict TMZ sensitivity in 9 out of 16 cell lines (56\%). The qMSP results matched well with TMZ sensitivity in II out of 12 (92\%) glioma cell lines. In addition, methylation as detected by bisulphite sequencing seemed to be predictive of TMZ sensitivity in all six cell lines analysed (100\%).

CONCLUSION: The MGMT protein expression more than MGMT promoter methylation status predicts the response to TMZ in human tumour cell lines.

British Journal of Cancer (2010) I 03, 29-35. doi:I0.1038/sj.bjc.66057I2 www.bjcancer.com

Published online I June 2010

(C) 2010 Cancer Research UK

Keywords: MGMT; temozolomide; glioma; prediction

Glioblastoma multiforme (GBM) is the most frequent and most malignant primary brain tumour. Despite surgery, adjuvant radiotherapy and chemotherapy, GBM often recur. Addition of temozolomide (TMZ) to fractionated radiotherapy for newly diagnosed GBM improved the median survival from 12 to 14 months and the 5 -year overall survival from 1.9 to $9.8 \%$ (Stupp et al, 2005, 2009).

TMZ, an alkylating cytostatic drug, acts through methylation of the $\mathrm{O}^{6}$ position of guanine; the resulting DNA lesions are considered to be responsible for the cytotoxic effect (Stevens et al, 1987; Tisdale, 1987). Presence of the DNA repair protein $\mathrm{O}^{6}$-methylguanine-DNA methyltransferase (MGMT) can cause resistance to alkylating agents, including TMZ, by removing the methyl group from the $\mathrm{O}^{6}$ position of guanine (Brennand and Margison, 1986).

Both transcriptional silencing of the MGMT gene by methylation of the $\mathrm{CpG}$ dinucleotides ( $\mathrm{CpGs}$ ) in the promoter region as well as absence of MGMT protein have been associated with a good clinical response to alkylating agents in general and in particular to TMZ in patients with an anaplastic astrocytoma or GBM (Esteller et al, 2000; Hegi et al, 2005; Chinot et al, 2007; Nagane et al, 2007; Sadones et al, 2009). However, the few studies comparing different

*Correspondence: KA van Nifterik; E-mail: ka.vannifterik@vumc.nl Revised 5 May 20 I0; accepted 6 May 20 I0; published online I June 2010 approaches to determination of the MGMT status all show a lack of correlation between MGMT protein expression and MGMT promoter methylation (Brell et al, 2005; Jeuken et al, 2007; Preusser et al, 2008; Rodriguez et al, 2008; Yachi et al, 2008).

Prediction of the TMZ sensitivity in clinical tumour samples would greatly improve the patients' treatment. However, to have clinical value, such an assay needs to be accurate, reliable and relatively convenient.

The purpose of this study was to determine whether the in vitro cytotoxic response to TMZ, evaluated by clonogenic assay, is associated with either MGMT expression and/or promoter methylation. In a panel of 16 human cancer cell lines, mostly derived from human GBM, MGMT protein expression was measured by western blot analysis. The MGMT promoter methylation levels were assayed by methylation-specific multiplex ligation-dependent probe amplification (MS-MLPA), methylation-specific PCR (MSP), quantitative real-time MSP (qMSP) and bisulphite sequencing.

\section{MATERIALS AND METHODS}

\section{Cell lines}

Sixteen cell lines were cultured at $37^{\circ} \mathrm{C}$ in medium containing foetal calf serum (FCS), $2 \mathrm{mmoll}^{-1}$ L-glutamine, $100 \mathrm{IU} \mathrm{ml}^{-1}$ 
penicillin and $100 \mathrm{IU} \mathrm{ml}^{-1}$ streptomycin (all from Invitrogen, Groningen, The Netherlands). The PC-3 cell line (prostate adenocarcinoma) was cultured in RPMI-1640 medium with $10 \%$ FCS. A-431 (epidermoid carcinoma), Gli-6 (GBM; Fehlauer et al, 2000) and HT-29 (colorectal adenocarcinoma) were cultured in Dulbecco's modified Eagle's medium (D-MEM) with 10\% FCS. In D-MEM with $20 \%$ FCS, AMC 3046, AMC 3344, VU-28, VU-98, VU-109, VU-110 and VU-122 were cultured (all GBM; van Nifterik et al, 2007). The above-mentioned 11 cell lines were cultured in a $7 \% \mathrm{CO}_{2}$-humidified atmosphere. Furthermore, five cell lines were cultured in a humidified atmosphere without $\mathrm{CO}_{2}$ using Leibovitch L15 medium with 10\% FCS: D384 (astrocytoma grade III; Balmforth et al, 1986), Hs 683 (GBM), SW 1573 (alveolar cell carcinoma), T98G (GBM) and U251 (GBM). Experiments were performed on cells from the same batch with the same cell passage number, except for western blot analysis of the T98 cell line.

\section{Clonogenic cell survival after TMZ treatment}

The experiment was performed as described earlier (van Nifterik et al, 2007). After $24 \mathrm{~h}$ exposure of TMZ, the medium was replaced either with fresh conditioned medium (AMC 3046, VU-109 and VU-110) or fresh normal medium (all other cell lines) for the remaining part of the clonogenic assay. Average plating efficiencies (for the untreated cell lines) were 50\% (A-431), 17\% (AMC 3046), 12\% (AMC 3344), 62\% (D384), 49\% (Gli-6), 30\% (HS683), 67\% (HT-29), 40\% (PC-3), 56\% (SW1573), 42\% (T98), 33\% (U251), 4\% (VU-28), 7\% (VU-98), 16\% (VU-109), 6\% (VU-110) and 36\% (VU-122). The results for AMC 3046, AMC 3344, VU-28, VU-98, VU-109, VU-110 and VU-122 have already been published (van Nifterik et al, 2007).

\section{MGMT protein expression by western blot analysis}

The analysis was performed as described earlier (van Nifterik et al, 2007) except that for the cell line HT-29, because of an abundance of targeted protein, $25 \mu \mathrm{g}$ instead of $50 \mu \mathrm{g}$ of protein sample were used. For western blot analysis of AMC 3344 also $100 \mu \mathrm{g}$ of protein were used. Colon carcinomas, in this study HT-29, are a positive control for the MGMT protein. Membranes were checked for successful protein transfer and loading control by incubation of the membranes for $1 \mathrm{~min}$ in ponceau $\mathrm{S}$.

\section{Methylation analysis}

MGMT promoter methylation analysis by MS-MLPA The MS-MLPA is a semi-quantitative method for methylation profiling using a methylation-sensitive restriction enzyme (Nygren et al, 2005). The SALSA MS-MLPA kit ME011 (MRC-Holland, Amsterdam, The Netherlands) was used to determine the promoter methylation status of the MGMT gene. The kit contains three different probes that specifically target three CpGs within the MGMT promoter region (Figure 1): MS-MLPA A, MS-MLPA B and MS-MLPA C, located from -459 to $-458,-313$ to -312 and 72 to 73 base pairs (bp) from the transcription start site (TSS), respectively. The MS-MLPA was performed with approximately $100 \mathrm{ng}$ DNA according to the protocol provided by the manufacturer. The amplified PCR products were separated by electrophoresis on an ABI PRISM 3730 fragment analyser (Applied Biosystems, Foster City, CA, USA) and analysed using Genemarker analysis software version 1.5 (SoftGenetics, LLC, State College, PA, USA). Data are presented in percentage of methylation (mean of two independent experiments) and classified as low $(0-40 \%)$, intermediate $(40-75 \%)$ and high $(75-100 \%)$.

MGMT promoter methylation analysis by MSP Methylationspecific PCR is based on the amplification of bisulphite-converted DNA, which can distinguish specifically between methylated and unmethylated DNA with a high sensitivity (Herman et al, 1996). Genomic DNA isolated from cell lines was subjected to bisulphite modification using the EZ DNA Methylation kit (Zymo Research, Orange, CA, USA) according to the protocol provided by the manufacturer. Sodium bisulphite converts unmethylated cytosines to uracils, whereas methylated cytosines are unaffected. Two MSPs were performed targeting two CpG-rich regions within the MGMT promoter using primer sets listed in Table 1 . The forward primers of MSP1 (3 CpGs) and MSP 2 (5 CpGs; Esteller et al, 1999) each contain a $\mathrm{CpG}$ that is also detectable by MS-MLPA probes A and C, respectively (Figure 1 ). The housekeeping gene $\beta$-actin (ACTB) was used as internal control of both bisulphite conversion DNA quality (Harden et al, 2003). In the reaction, $50 \mathrm{ng}$ bisulphitetreated genomic DNA was amplified with FastStart Taq PCR buffer (Roche Diagnostics, Almere, The Netherlands) with $1.5 \mathrm{mM} \mathrm{MgCl}_{2}$, $0.5 \mu \mathrm{M}$ primers, each dNTP at $200 \mu \mathrm{M}$, and $1.25 \mathrm{U}$ of FastStart Taq DNApolymerase in a total volume of $25 \mu \mathrm{l}$. Amplification reaction was carried out in a GeneAmp PCR system 9700 using the following conditions: $95^{\circ} \mathrm{C}$ for $4 \mathrm{~min}$, followed by 38 (MSP1 and MSP2) or 40 (ACTB) cycles of $95^{\circ} \mathrm{C}$ for $30 \mathrm{~s}, 61^{\circ} \mathrm{C}$ (MSP1) or $59^{\circ} \mathrm{C}$ (MSP2) or $60^{\circ} \mathrm{C}$ (ACTB) for $30 \mathrm{~s}$ and $72^{\circ} \mathrm{C}$ for $45 \mathrm{~s}$, with a final extension of $72^{\circ} \mathrm{C}$ for $4 \mathrm{~min}$. The cervical cancer cell line CaSki (which is methylated for the MGMT gene) was used as positive control, whereas unmethylated (primary keratinocytes), unmodified DNA and $\mathrm{H}_{2} \mathrm{O}$ were included as negative controls. The PCR products were detected by UV light on a $2 \%$ agarose gel stained with ethidium bromide. A 100-bp DNA ladder (Amersham Biosciences, Buckinghamshire, UK) was used as a marker. All MSP reactions were performed in duplicate.

MGMT promoter methylation analysis by qMSP The qMSP is based on the same principle as MSP, but uses a probe, in this case a Taqman probe, for real-time quantification of amplification products (Vlassenbroeck et al, 2008). The primers and probe included in the qMSP are listed in Table 1 (see also Figure 1); the same primer set of MSP2 (Esteller et al, 1999) was used for the quantitative format. For the amplification reaction, $2.5 \mu \mathrm{l}$

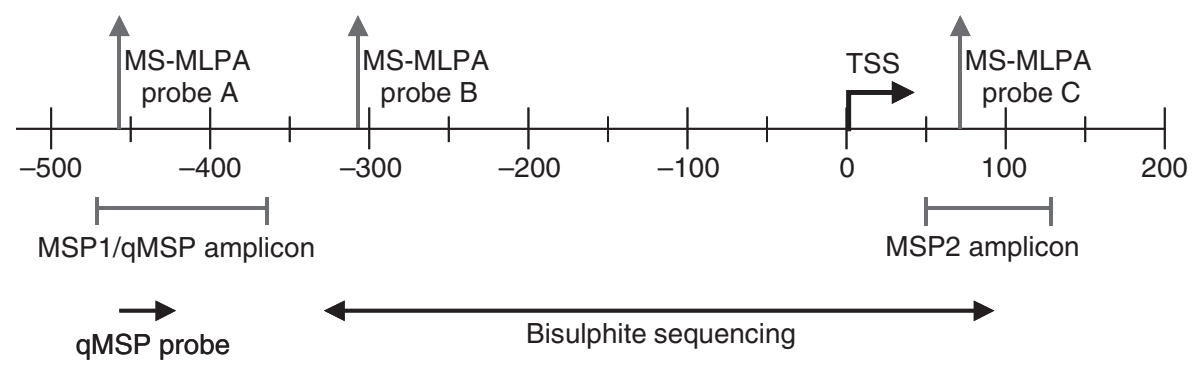

Figure I Locations on the MGMT promoter for the amplicons of the primer sets for MSPI/qMSP, MSP2, and bisulphite sequencing, and locations for probe qMSP and MS-MLPA probes A, B and C. TSS = transcription start site. 
Table I Primer and probe sequences, location and amplicon of MGMT gene promoter for the methylation-specific PCR (MSP), quantitative real-time MSP (qMSP) and primer sequences of MGMT promoter for bisulphite-sequencing technique

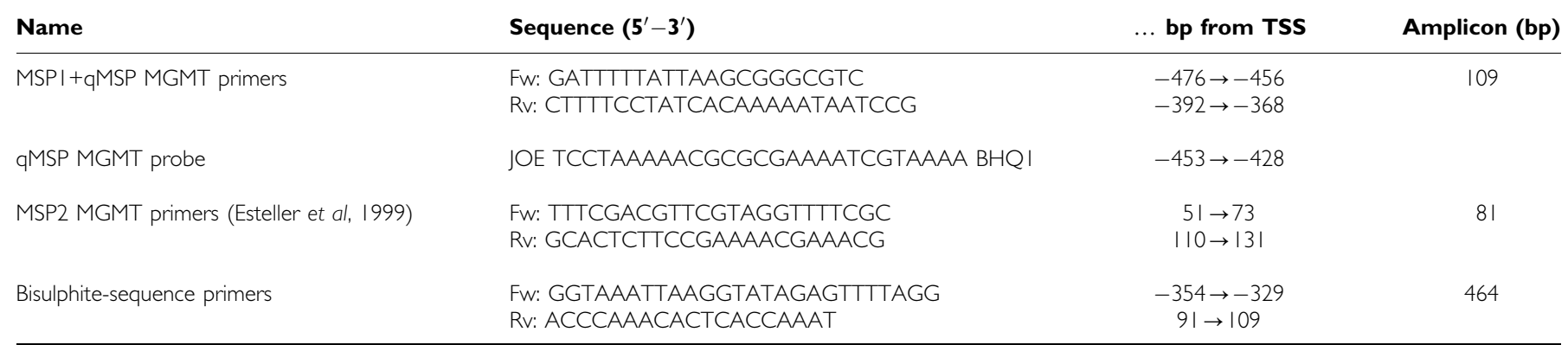

Abbreviations: TSS = transcription start site; $b p=$ base pairs; $F w=$ forward primer; $R v=$ reverse primer.

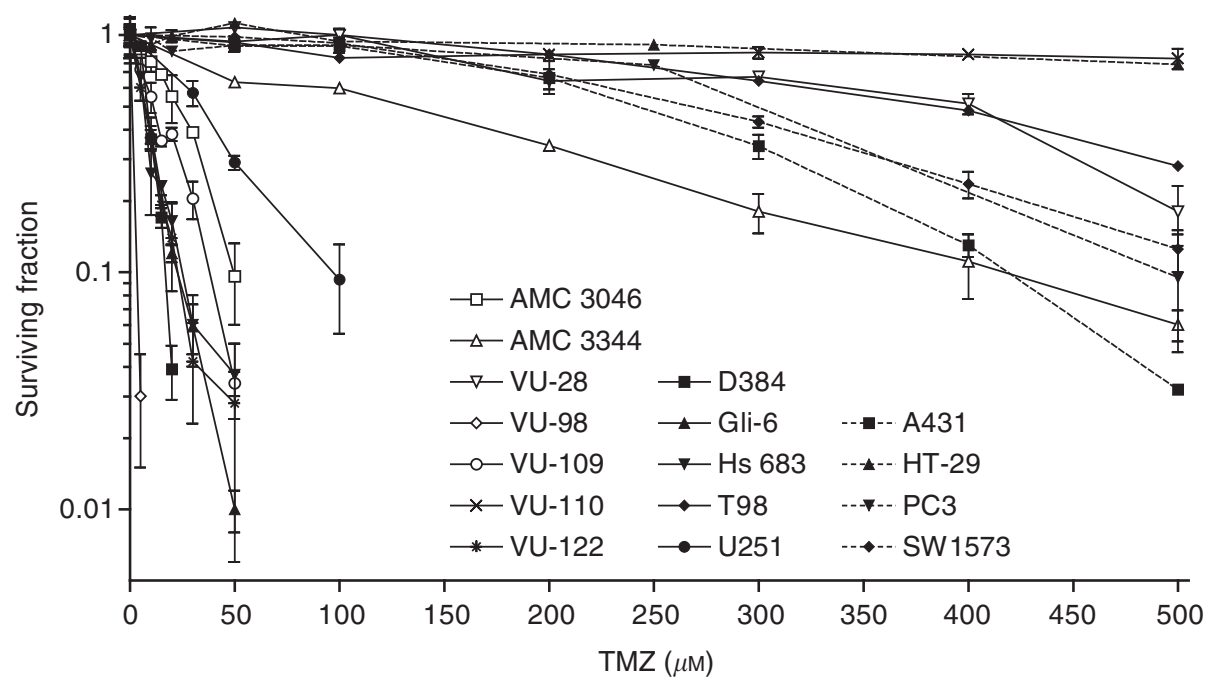

Figure 2 Clonogenic cell survival after $24 \mathrm{~h}$ exposure of 16 cancer cell lines to temozolomide (TMZ). The results for AMC 3046, AMC 3344, VU-28, VU-98, VU-109, VU-I I 0 and VU- 122 have already been published (van Nifterik et al, 2007). Error bars represent the mean \pm s.d. ( $n=2$ ).

bisulphite-treated DNA was added to $9.5 \mu$ l amplification mix containing $1 \times$ Quantitect Probe mix (Qiagen, Venlo, The Netherlands), $0.8 \mu \mathrm{M}$ of each primer and $0.208 \mu \mathrm{M}$ of the $5^{\prime} \mathrm{JOE} /$ 3'BHQ1-labelled probe. Amplification and real-time measurement were performed in the 7500 Fast $\mathrm{ABI}$ system under the following conditions: $15 \mathrm{~min}$ at $95^{\circ} \mathrm{C}$ followed by 45 cycles of $30 \mathrm{~s}$ at $95^{\circ} \mathrm{C}$ and $1 \mathrm{~min}$ at $60^{\circ} \mathrm{C}$. The reaction included multiple water blanks, as negative control, and serial dilutions of the CaSki cell line. As reference, the gene $A C T B$ was used to control bisulphite conversion and total input DNA (Harden et al, 2003). Promoter methylation levels were calculated with the formula [(target gene/ $A C T B) \times 1000$ ]. The cutoff value for discrimination between methylation levels was $>200=$ methylated, and $<200=$ unmethylated or low methylated. All samples were tested in duplicate. When discrepant results were obtained, the samples were analysed in quadruplicate and scored positive if at least two reactions were positive.

MGMT promoter methylation analysis by bisulphite sequencing Bisulphite sequencing was performed in an area of the MGMT promoter not tested before with MS-MLPA, MSP or qMSP (Figure 1). For bisulphite-sequencing analysis, bisulphite-treated genomic DNA of the GBM cell lines AMC 3344, VU-28, VU110, Hs 683 , U251 and the astrocytoma grade III cell line D384 (selected on the basis of the results of western blot and MS-MLPA) was amplified using primers listed in Table 1. The PCR mixtures contained $50 \mathrm{ng}$ bisulphite-treated genomic DNA, FastStart Taq
PCR buffer (Roche Diagnostics) with $1.5 \mathrm{mM} \mathrm{MgCl}_{2}, 0.5 \mu \mathrm{M}$ primers, each dNTP at $200 \mu \mathrm{M}$, and $1.25 \mathrm{U}$ of FastStart Taq DNApolymerase in a total volume of $25 \mu \mathrm{l}$. Amplification reaction was carried out in a GeneAmp PCR system 9700 using the following conditions: $95^{\circ} \mathrm{C}$ for $4 \mathrm{~min}$, followed by 40 cycles of $95^{\circ} \mathrm{C}$ for $30 \mathrm{~s}, 55^{\circ} \mathrm{C}$ for $30 \mathrm{~s}$ and $72^{\circ} \mathrm{C}$ for $45 \mathrm{~s}$, with a final extension of $72^{\circ} \mathrm{C}$ for $4 \mathrm{~min}$. Amplified PCR products were purified using the ExoI and SAP (USB Europe GmbH, Staufen, Germany) according to the manufacturer's specifications, and were sequenced directly using the forward or the reverse primer and the BigDye Terminator v3.1 Cycle Sequencing kit (Applied Biosystems). After each sample was purified with the BigDye XTerminator Purification kit, each sequencing product was subsequently analysed by electrophoresis in the 3130 Genetic Analyser (Applied Biosystems). Sixty-two CpGs were analysed, that is every CpG located between -329 and $+91 \mathrm{bp}$ from the TSS.

\section{RESULTS}

\section{Clonogenic cell survival after TMZ treatment}

A panel of 16 human tumour cell lines, including 12 gliomas (11 GBM and 1 astrocytoma grade III) and 4 other carcinoma cell lines, was tested for their response to $24 \mathrm{~h}$ treatment with different concentrations of TMZ. Cell survival data presented in Figure 2 show that two distinct groups of cell lines can be distinguished: TMZ 
sensitive and TMZ resistant. The two separate groups can also be shown by ascertaining the surviving fraction (SF) of the cell lines after exposure to $250 \mu \mathrm{M} \mathrm{TMZ}$, as depicted in Table 2. Cell lines that did not survive this treatment $(S F=0)$ were defined as sensitive for TMZ, whereas cell lines showing at least an SF of 0.4 were considered TMZ resistant.

\section{MGMT protein expression}

Sixteen cell lines were tested for expression of the MGMT protein by western blot analysis to investigate its ability to predict cell survival after TMZ exposure. As shown in Figure 3A, eight cell lines exhibit expression of the MGMT protein, including four GBM (AMC 3344, VU-28, VU-110 and T98) and four other carcinomas (A-431, HT-29, PC-3 and SW1573). The levels of expression ranged from high (HT-29) to (very) low (AMC 3344). The other eight cell lines (7 GBM and 1 astrocytoma grade III) did not express detectable levels of the MGMT protein. The MGMT protein was detected in all TMZ-resistant cell lines, whereas no MGMT protein could be detected in cell lines that were TMZ sensitive.

\section{Methylation analysis}

To determine the methylation status of the promoter of the MGMT gene, several techniques were used: MS-MLPA (semi-quantitative), MSP, qMSP (quantitative) and bisulphite sequencing.

MGMT promoter methylation analysis by MS-MLPA The promoter methylation levels in all 16 cell lines as determined by MS-MLPA were obtained using three probes (directed against different CpGs in the MGMT promoter). The mean results of two independent experiments are shown in Table 2. Most regions with low methylation levels $(0-40 \%)$ were found in the group of cell lines that were resistant to TMZ. However, low methylation levels were also found for probe B in the TMZ-sensitive cell lines VU-98 and VU-122. In contrast, high methylation levels (75-100\%) were found mainly in the group of cell lines that were sensitive for TMZ.
However, high methylation levels were also found for probe A in the TMZ-resistant cell lines HT-29, SW 1573 and T98. The areas with intermediate methylation levels $(40-75 \%)$ appeared in both TMZ sensitive and resistant cell lines. A limited association between TMZ sensitivity and MGMT promoter methylation was found (Table 2). Presence of at least 2 out of 3 low $(0-40 \%)$ methylated CpGs determined resistance to TMZ in 5 out of 8 cell lines (63\%). Cell lines sensitive to TMZ could only be predicted when at least 2 out of 3 CpGs were highly (75-100\%) methylated. This was the case in 4 out of 8 cell lines (50\%). For none of the inbetween results (i.e. all other combinations of low, intermediate, and high methylated CpGs) was a match found with sensitivity for TMZ in 7 out of 16 cell lines (44\%). Overall, MS-MLPA was predictive for TMZ sensitivity in 9 out of 16 cell lines (56\%).

MGMT promoter methylation analysis by MSP Two different primer sets for different locations within the $M G M T$ promoter were used to determine the methylation status by MSP. The MSP1 covers the MS-MLPA probe A and MSP2 covers MS-MLPA probe $C$ (see Figure 1). The results for the primer sets MSP1 and MSP2 (Table 2; Figure $3 \mathrm{~B}$ ) showed methylation positivity for all but two cell lines. Although most cell lines tested positive, there was a clear difference in intensity of PCR products detected. Apparently, the MSP assays are very sensitive, thus necessitating a quantitative assay to allow a better discrimination between the levels of MGMT methylation.

MGMT promoter methylation analysis by qMSP The qMSP probe was designed for the MSP1 region to gain insight into the relative methylation levels in this region of the promoter of the MGMT gene. The methylation levels as determined by qMSP are presented as ratios, which indicate the relative amount of methylated MGMT (as compared with $A C T B$ ). The results are shown in Table 2. The ratios for the TMZ-resistant group range from 10.49 to 1338.38 , whereas the ratios for the TMZ-sensitive group range from 244.83 to 1460.92. All eight cell lines sensitive to TMZ showed methylation $(>200)$. The four GBM cell lines that were resistant to TMZ

Table 2 Temozolomide (TMZ) sensitivity (SF after $250 \mu \mathrm{M}$ TMZ), MGMT promoter methylation status assessed by methylation-specific PCR (MSP), methylation-specific multiplex ligation-dependent probe amplification (MS-MLPA), quantitative real-time MSP (qMSP) and western blot (WB) results for a panel of cancer cell lines

\begin{tabular}{|c|c|c|c|c|c|c|c|c|}
\hline \multirow[b]{2}{*}{ Cell line } & \multirow[b]{2}{*}{$\begin{array}{c}250 \mu \mathrm{M} T M Z \\
(\mathrm{SF} \pm \text { s.d.) }\end{array}$} & \multirow{2}{*}{$\begin{array}{c}\text { WB } \\
\text { MGMT } \\
\text { expression }\end{array}$} & \multicolumn{3}{|c|}{ MS-MLPA ( $\%$ methylation \pm s.d.) } & \multicolumn{2}{|c|}{ MSP (level of methylation) } & \multirow{2}{*}{$\begin{array}{c}\text { qMSP } \\
\text { Ratio } \\
(\mathrm{mMGMT} / \\
\text { ACTB) } \times 1000\end{array}$} \\
\hline & & & MS-MLPA A & MS-MLPA B & MS-MLPA C & MSPI & MSP2 & \\
\hline A43I & $0.55 \pm 0.02$ & y & $66.5 \pm 1.5$ & $63.5 \pm 2.5$ & $64 \pm 1$ & ++ & ++ & 607.23 \\
\hline HТ-29 & $0.97 \pm 0.01$ & y & $94 \pm 0$ & 0 & 0 & ++ & - & 1169.76 \\
\hline PC3 & $0.75 \pm 0$ & y & 0 & 0 & 0 & - & + & 42.90 \\
\hline SWI573 & $0.44 \pm 0.06$ & y & $100 \pm 0$ & $73 \pm 5$ & 0 & ++ & ++ & 1338.38 \\
\hline AMC 3344 & $0.39 \pm 0.01$ & y & $12.5 \pm 12,5$ & 0 & $58 \pm 1$ & + & + & 31.32 \\
\hline VU-28 & $1.08 \pm 0.26$ & $y$ & 0 & 0 & 0 & + & + & 170.16 \\
\hline$V U-110$ & $0.93 \pm 0.01$ & y & 0 & 0 & 0 & - & - & 0 \\
\hline T98 & 0.74 & y & $99 \pm 1$ & $58.5 \pm 1.5$ & $55.5 \pm 5.5$ & ++ & + & 901.86 \\
\hline AMC 3046 & 0 & $n$ & $62 \pm 0$ & $59 \pm 1$ & $62 \pm 1$ & + & + & 510.35 \\
\hline D384 & 0 & $n$ & $83 \pm 1$ & $82 \pm 6$ & $92.5 \pm 1.5$ & ++ & ++ & 1460.92 \\
\hline Gli6 & 0 & $n$ & $48 \pm 2$ & $42.5 \pm 2.5$ & $63.5 \pm 5.5$ & ++ & ++ & 245.08 \\
\hline Hs 683 & 0 & $n$ & $97 \pm 3$ & $93 \pm 4$ & $98 \pm 2$ & ++ & ++ & 502.59 \\
\hline U25I & 0 & $n$ & $77.5 \pm 14,5$ & $66 \pm 2$ & $100 \pm 0$ & ++ & ++ & 1243.66 \\
\hline VU-98 & 0 & $n$ & $51.5 \pm 0.5$ & $30 \pm 2$ & $97.5 \pm 2.5$ & + & ++ & 244.83 \\
\hline VU-I09 & 0 & $\mathrm{n}$ & $97.5 \pm 2.5$ & $43.5 \pm 4.5$ & $100 \pm 0$ & + & ++ & 808.58 \\
\hline VU-I22 & 0 & $\mathrm{n}$ & $45 \pm 3$ & 0 & $41 \pm 6$ & + & + & 297.38 \\
\hline
\end{tabular}

Abbreviations: SF = surviving fraction; s.d. = standard deviation; $-=$ unmethylated; $+=$ methylated; $++=$ highly methylated; MGMT = ${ }^{6}$-methylguanine-DNA methyltransferase; $\mathrm{mMGMT}=$ methylated MGMT promoter; $A C T B=\beta$-actin gene; MS-MLPA results: white $=$ unmethylated, grey $=$ methylated, dark $=$ highly methylated; $y=$ yes; $\mathrm{n}=$ no. 
A

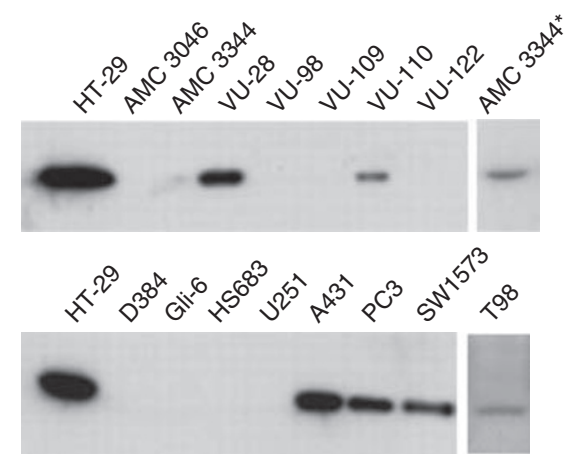

C

C MGMT
AMC 3344

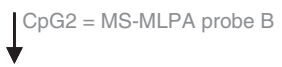

VU-28

VU-110

$-\infty 000000000000000000$
$-\infty 000000000000000$

$-000000000000000000000000000000$

\section{B}

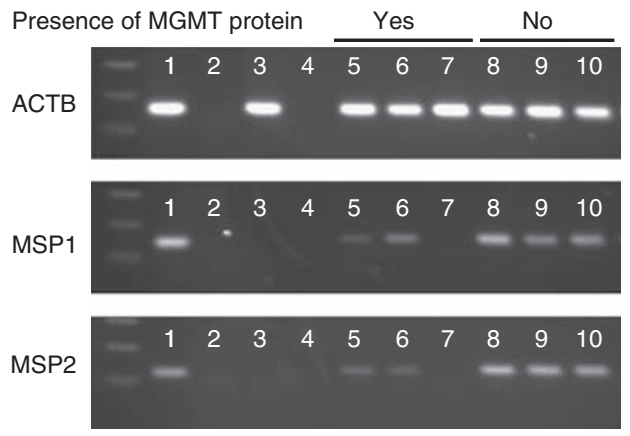

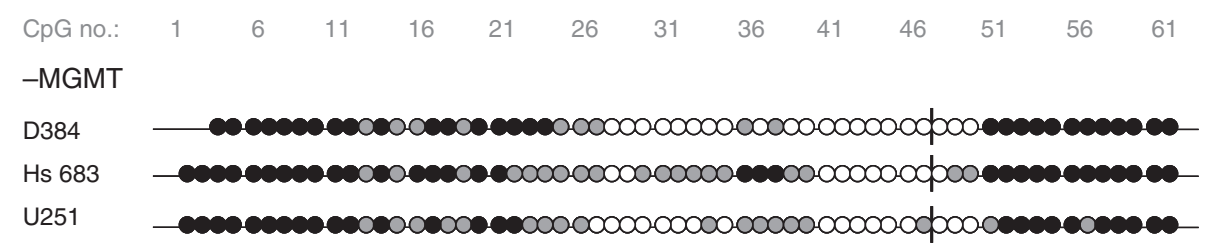

Figure 3 (A) Western blot analysis for the expression of $\mathrm{O}^{6}$-methylguanine-DNA methyltransferase (MGMT) on a panel of four carcinoma (A-43I, HT-29, PC-3 and SWI573) and 12 glioma cell lines. For all samples, $50 \mu \mathrm{g}$ of total protein were tested, except for the cell line HT-29 (25 $\mu \mathrm{g})$. The AMC 3344* was also analysed with $100 \mu$ g. (B) Methylation-specific PCR (MSP) results for the MGMT gene promoter using the primer sets MSPI, MSP2 en control (ACTB) for a selection of six cell lines. I: CaSki (cervical cancer cell line/positive control), 2: unmodified DNA (negative control), 3: unmethylated DNA (primary keratinocytes/negative control), 4: $\mathrm{H}_{2} \mathrm{O}$, 5: AMC 3344, 6: VU-28, 7: VU-I I0, 8: D384, 9: HS683, I0: U25I. (C) Summary of bisulphite sequencing in six GBM cell lines (three with MGMT expression and three without). A total of 62 CpG dinucleotides (CpGs) within the promoter region of MGMT were analysed and are represented as circles. Each row represents one individual cell line. Closed circles represent cytosine (methylated), open circles represent uracil (unmethylated) and grey circles represent a peak with both cytosine and uracil.

showed no or low methylation levels $(<200)$, except for cell line T98. For the four non-glioma cell lines, the opposite was found, these cell lines showed high levels of methylation, except for cell line PC-3 (1 out of 4 cell lines (25\%)). Therefore, no association was found between the qMSP data and the cytotoxic response of the non-glioma cell lines to $250 \mu \mathrm{M}$ TMZ. The TMZ-resistant GBM cell lines (with the exception of T98) and the TMZ-sensitive glioma cell lines showed a good relationship between qMSP data and the cytotoxic response to TMZ (11 out of 12 cell lines (92\%)). The qMSP data also showed a good association with data from MS-MLPA probe A.

MGMT promoter methylation analysis by bisulphite sequencing On the basis of the results of earlier analyses (Table 2), six GBM cell lines (three with and three without expression of the MGMT protein) were analysed by bisulphite sequencing (in total $62 \mathrm{CpGs}$; see Figure 1). A summary of the bisulphite sequence results is shown in Figure 3C. All 62 CpGs were completely unmethylated in cell line AMC 3344 and almost completely unmethylated in cell lines VU-28 and VU-110. Unfortunately, we were not able to interpret the results at the $3^{\prime}$ end of the PCR product in these cell lines. In the MGMT-negative cell lines D384, Hs 683 and U251, the 25 CpGs $(2-26)$ located at the $5^{\prime}$ end $(-313 \rightarrow-153$ bp from TSS) were completely methylated or contained both methylated and unmethylated CpGs. In addition, the 12 CpGs (51-62) located at the $3^{\prime}$ end were completely or almost completely methylated $(+29 \rightarrow+90$ bp from TSS). Methylation levels in these two CpG locations seem to correlate well with TMZ sensitivity. No or partial methylation was detected at CpGs 27-50. The $5^{\prime}$ and $3^{\prime}$ region cover the MS-MLPA probes B (CpG 2) and C (CpG 59) and these bisulphite-sequencing results show an excellent relationship with data from MS-MLPA probe B and MS-MLPA probe C. Bisulphite sequencing predicted TMZ sensitivity in all six tested cell lines $(100 \%)$.

\section{DISCUSSION}

In this study, we determined the sensitivity to TMZ, assessed by clonogenic cell survival, in a panel of human tumour cell lines, mostly derived from GBM. Sensitivity of TMZ correlated with the MGMT promoter methylation status (assessed by MS-MLPA, MSP, qMSP and bisulphite sequencing) and MGMT protein expression (western blot).

Methylation of the CpGs in the promoter region of the MGMT gene can cause transcriptional silencing, resulting in an absent gene product (i.e. the MGMT protein), which in turn is responsible for failure of repair of the (TMZ-induced) $\mathrm{O}^{6}$-methylated guanine lesions in the DNA. Transcriptional silencing of the MGMT gene by promoter methylation has been shown in cell lines as well as in human tumour tissues (Qian and Brent, 1997; Watts et al, 1997; Esteller et al, 1999). The fact that in this study, the absence of the protein indeed reflected cells that are sensitive to TMZ, as shown in Figure 4, agrees with these earlier findings. It is worth noting that expression of the MGMT protein showed a $100 \%$ positive match with TMZ resistance, with undetectable levels of MGMT protein in TMZ-sensitive cells and varying levels of MGMT protein in TMZ-resistant cells. 
34

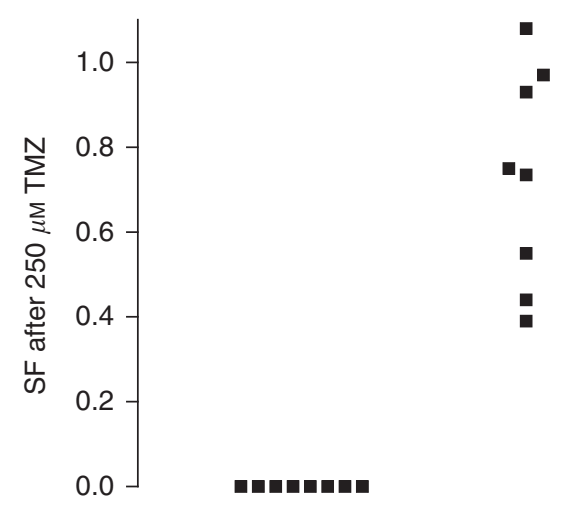

No MGMT protein MGMT protein

Figure 4 The relationship between temozolomide (TMZ) sensitivity (as indicated by the surviving fraction (SF) after $24 \mathrm{~h}$ of $250 \mu \mathrm{M} \mathrm{TMZ}$ ) and $\mathrm{O}^{6}$-methylguanine-DNA methyltransferase (MGMT) protein expression as determined by western blot analysis.

Similarly, Hermisson et al (2006) showed that MGMT activity correlated with MGMT expression and clonogenic survival after TMZ exposure in human glioma cells. Although Bobola et al (1996) showed that MGMT is a determinant of resistance in medulloblastoma and glioma-derived cell lines, they found disparity in the contribution of MGMT to TMZ sensitivity. They state that the lack of correlation between the amount of MGMT expression and the degree of sensitivity to TMZ, and the variability in cytotoxicity in cell lines without MGMT indicate that other factors are involved in resistance. This could also be the case in the cell lines tested in our study, as we found disparities that were similar to those of Bobola et al (1996). For instance, the mismatch repair system or p53 could also be involved in resistance to TMZ in glioma cells.

This study shows that the detection of DNA methylation as a predictor of TMZ response is highly dependent on the technique used and the CpGs analysed. The probes of MS-MLPA had limited predictability (56\%). Using MSP in a conventional manner seemed too sensitive, whereas conversion to a quantitative assay (qMSP) enabled a better prediction for glioma cells (92\%) based on levels of methylation. Bisulphite-sequencing analysis predicted TMZ sensitivity in all tested samples $(100 \%)$ and confirmed that MGMT methylation is heterogeneous, as even in the TMZ-resistant cell lines, there are regions in the MGMT promoter that remain unmethylated, that is from CpGs 27 to 50. Consequently, these regions should be avoided when designing methylation assays for clinical applications. Furthermore, bisulphite sequencing confirmed qMSP and part of the MS-MLPA results and showed two important regions in the promoter of the MGMT gene that are of interest for the relationship between $M G M T$ promoter methylation and silencing of the MGMT gene. First, the regions in the promoter indicated by the primers and probe of the qMSP technique $(-392 \rightarrow-368$ bp from TSS) extended with the location of CpGs 1 to 26 as analysed by bisulphite sequencing $(-328 \rightarrow-153 \mathrm{bp}$ from TSS), including the CpGs from MS-MLPA probes A and B. The second area is located upstream from the TSS covered by CpGs 51 to 62 as analysed by bisulphite sequencing and by the MSP2 primers, also including the CpG from MS-MLPA probe $\mathrm{C}(+29 \rightarrow$ +131 bp from TSS). This information can be used to design new primers and/or probes for MS-MLPA and/or qMSP.

In the literature, a limited amount of CpGs is usually tested for determination of the methylation status. The MSP primer set used in this study (MSP2) has been used in other studies (Esteller et al, 1999, 2000; Brell et al, 2005; Jeuken et al, 2007; Rodriguez et al, 2008; Yachi et al, 2008). Primer sets that are also often used are located close to or in the same area as MSP2 (Hegi et al, 2005;
Vlassenbroeck et al, 2008; Dunn et al, 2009; Sadones et al, 2009). Although this seems to be a good location for analysis of methylation patterns, perhaps other and/or more combinations of methylated CpGs would be better predictors of blocking transcription of the $M G M T$ gene, hence silencing the gene, which may predict TMZ sensitivity. For instance, the area farther downstream of the TSS ( $-392 \rightarrow-153$ bp from TSS) may also prove to be of interest.

Studies with human glioma tumour samples often revealed a lack of correlation between MGMT protein expression and MGMT promoter methylation status (Brell et al, 2005; Jeuken et al, 2007; Preusser et al, 2008; Rodriguez et al, 2008; Yachi et al, 2008). Nevertheless, patient studies that investigated the relationship between either MGMT protein expression or MGMT promoter methylation and survival of patients with a GBM who had received TMZ as adjuvant chemotherapy have shown promising results. For instance, two studies showed a (negative) correlation between MGMT protein expression and patient survival (Chinot et al, 2007; Nagane et al, 2007). Other studies found that MGMT promoter methylation correlated with patient survival (Hegi et al, 2005; Dunn et al, 2009; Sadones et al, 2009).

Often no correlation is found between promoter methylation and protein expression and both can have prognostic significance in relation to survival of patients treated with TMZ for GBM. Possible explanations may be found in imperfections of the experiment design and/or techniques used. In case of promoter methylation analysis, the promoter region chosen to be investigated may be of influence on the outcome, as described before. In this respect, the technique of MS-MLPA is, despite all its advantages, limited as it can only determine the methylation status of CpGs that are situated within an HhaI restriction site. Furthermore, MSP analysis results may fail in a significant amount of the samples (Hegi et al, 2005; Rodriguez et al, 2008). Another aspect of many techniques is that differences in MGMT status between individual cells cannot be detected, even though several studies have shown the intratumoural heterogeneity of human gliomas for MGMT protein expression (Citron et al, 1991; Belanich et al, 1996). Moreover, discrimination between tumour and non-tumour cells in clinical tumour samples is not possible with many of the techniques used and the outcome may be distorted by contamination with non-tumour cells. Techniques such as MSP, qMSP, bisulphite sequencing and WB cannot discriminate. In vitro studies, as the present one, do not have this complication, as tumour cell lines are pure neoplastic cell populations. In this respect, immunohistochemistry, determining the expression of the MGMT protein per individual cell, may be a better technique for screening human tumour samples. Nevertheless, immunohistochemistry also has disadvantages, as reported in several studies (Jeuken et al, 2007; Capper et al, 2008; Preusser et al, 2008; Rodriguez et al, 2008). Among others, problems were reported with interobserver variability and interpretation of MGMT expressing non-neoplastic infiltrating cells. In addition, suitable techniques such as bisulphite sequencing are often too complex, time consuming and expensive for routine application on tumour samples. On the other hand, techniques such as MSP or immunohistochemistry are easy-to-use and cost-efficient, but have other disadvantages.

In conclusion, MGMT protein expression more than the level of $M G M T$ promoter methylation predicts the response to TMZ in human tumour cell lines. Future research should focus on gaining more knowledge of methylation patterns in the promoter region and their relationship with protein expression. In this respect, choosing the appropriate assay that will be accurate, reliable and convenient enough will be of great importance for application in the clinical setting.

\section{ACKNOWLEDGEMENTS}

Temozolomide was a generous gift from Schering-Plough RS. This work was supported by the Dutch Cancer Society Grant No. VU 2000-2149. 


\section{REFERENCES}

Balmforth AJ, Ball SG, Freshney RI, Graham DI, McNamee HB, Vaughan PF (1986) D-1 dopaminergic and beta-adrenergic stimulation of adenylate cyclase in a clone derived from the human astrocytoma cell line G-CCM. J Neurochem 47: 715-719

Belanich M, Randall T, Pastor MA, Kibitel JT, Alas LG, Dolan ME, Schold Jr SC, Gander M, Lejeune FJ, Li BF, White AB, Wasserman P, Citron ML, Yarosh DB (1996) Intracellular localization and intercellular heterogeneity of the human DNA repair protein $\mathrm{O}(6)$-methylguanine-DNA methyltransferase. Cancer Chemother Pharmacol 37: 547-555

Bobola MS, Tseng SH, Blank A, Berger MS, Silber JR (1996) Role of O6methylguanine-DNA methyltransferase in resistance of human brain tumor cell lines to the clinically relevant methylating agents temozolomide and streptozotocin. Clin Cancer Res 2: 735-741

Brell M, Tortosa A, Verger E, Gil JM, Viñolas N, Villá S, Acebes JJ, Caral L, Pujol T, Ferrer I, Ribalta T, Graus F (2005) Prognostic significance of O6methylguanine-DNA methyltransferase determined by promoter hypermethylation and immunohistochemical expression in anaplastic gliomas. Clin Cancer Res 11: 5167 - 5174

Brennand J, Margison GP (1986) Reduction of the toxicity and mutagenicity of alkylating agents in mammalian cells harboring the Escherichia coli alkyltransferase gene. Proc Natl Acad Sci USA 83: $6292-6296$

Capper D, Mittelbronn M, Meyermann R, Schittenhelm J (2008) Pitfalls in the assessment of MGMT expression and in its correlation with survival in diffuse astrocytomas: proposal of a feasible immunohistochemical approach. Acta Neuropathol 115: 249-259

Chinot OL, Barrié M, Fuentes S, Eudes N, Lancelot S, Metellus P, Muracciole X, Braguer D, Ouafik L, Martin PM, Dufour H, Figarella-Branger D (2007) Correlation between O6-methylguanine-DNA methyltransferase and survival in inoperable newly diagnosed glioblastoma patients treated with neoadjuvant temozolomide. J Clin Oncol 25: 1470 - 1475

Citron M, Decker R, Chen S, Schneider S, Graver M, Kleynerman L, Kahn LB, White A, Schoenhaus M, Yarosh D (1991) O6-methylguanineDNA methyltransferase in human normal and tumor tissue from brain, lung, and ovary. Cancer Res 51: $4131-4134$

Dunn J, Baborie A, Alam F, Joyce K, Moxham M, Sibson R, Crooks D, Husband D, Shenoy A, Brodbelt A, Wong H, Liloglou T, Haylock B, Walker C (2009) Extent of MGMT promoter methylation correlates with outcome in glioblastomas given temozolomide and radiotherapy. $\mathrm{Br} J$ Cancer 101: $124-131$

Esteller M, Hamilton SR, Burger PC, Baylin SB, Herman JG (1999) Inactivation of the DNA repair gene O6-methylguanine-DNA methyltransferase by promoter hypermethylation is a common event in primary human neoplasia. Cancer Res 59: 793-797

Esteller M, Garcia-Foncillas J, Andion E, Goodman SN, Hidalgo OF, Vanaclocha V, Baylin SB, Herman JG (2000) Inactivation of the DNArepair gene MGMT and the clinical response of gliomas to alkylating agents. $N$ Engl J Med 343: $1350-1354$

Fehlauer F, Barten-Van Rijbroek AD, Stalpers LJ, Leenstra S, Lindeman J, Tjahja I, Troost D, Wolbers JG, van der Valk P, Sminia P (2000) Additive cytotoxic effect of cisplatin and X-irradiation on human glioma cell cultures derived from biopsy-tissue. J Cancer Res Clin Oncol 126: 711 - 716

Harden SV, Guo Z, Epstein JI, Sidransky D (2003) Quantitative GSTP1 methylation clearly distinguishes benign prostatic tissue and limited prostate adenocarcinoma. J Urol 169: 1138-1142

Hegi ME, Diserens AC, Gorlia T, Hamou MF, de Tribolet N, Weller M, Kros JM, Hainfellner JA, Mason W, Mariani L, Bromberg JE, Hau P, Mirimanoff RO, Cairncross JG, Janzer RC, Stupp R (2005) MGMT gene silencing and benefit from temozolomide in glioblastoma. $N$ Engl J Med 352: $997-1003$

Herman JG, Graff JR, Myöhänen S, Nelkin BD, Baylin SB (1996) Methylation-specific PCR: a novel PCR assay for methylation status of CpG islands. Proc Natl Acad Sci USA 93: 9821 - 9826

Hermisson M, Klumpp A, Wick W, Wischhusen J, Nagel G, Roos W, Kaina B, Weller M (2006) O6-methylguanine DNA methyltransferase and p53 status predict temozolomide sensitivity in human malignant glioma cells. J Neurochem 96: $766-776$

Jeuken JW, Cornelissen SJ, Vriezen M, Dekkers MM, Errami A, Sijben A, Boots-Sprenger SH, Wesseling P (2007) MS-MLPA: an attractive alternative laboratory assay for robust, reliable, and semiquantitative detection of MGMT promoter hypermethylation in gliomas. Lab Invest 87: $1055-1065$
Nagane M, Kobayashi K, Ohnishi A, Shimizu S, Shiokawa Y (2007) Prognostic significance of O6-methylguanine-DNA methyltransferase protein expression in patients with recurrent glioblastoma treated with temozolomide. Jpn J Clin Oncol 37: 897-906

Nygren AO, Ameziane N, Duarte HM, Vijzelaar RN, Waisfisz Q, Hess CJ, Schouten JP, Errami A (2005) Methylation-specific MLPA (MS-MLPA): simultaneous detection of $\mathrm{CpG}$ methylation and copy number changes of up to 40 sequences. Nucleic Acids Res 33: e128

Preusser M, Charles Janzer R, Felsberg J, Reifenberger G, Hamou MF, Diserens AC, Stupp R, Gorlia T, Marosi C, Heinzl H, Hainfellner JA, Hegi M (2008) Anti-O6-methylguanine-methyltransferase (MGMT) immunohistochemistry in glioblastoma multiforme: observer variability and lack of association with patient survival impede its use as clinical biomarker. Brain Pathol 18: 520-532

Qian XC, Brent TP (1997) Methylation hot spots in the $5^{\prime}$ flanking region denote silencing of the O6-methylguanine-DNA methyltransferase gene. Cancer Res 57: $3672-3677$

Rodriguez FJ, Thibodeau SN, Jenkins RB, Schowalter KV, Caron BL, O'neill BP, David James C, Passe S, Slezak J, Giannini C (2008) MGMT immunohistochemical expression and promoter methylation in human glioblastoma. Appl Immunohistochem Mol Morphol 16: 59-65

Sadones J, Michotte A, Veld P, Chaskis C, Sciot R, Menten J, Joossens EJ, Strauven T, D'Hondt LA, Sartenaer D, Califice SF, Bierau K, Svensson C, De Grève J, Neyns B (2009) MGMT promoter hypermethylation correlates with a survival benefit from temozolomide in patients with recurrent anaplastic astrocytoma but not glioblastoma. Eur J Cancer 45: $146-153$

Stevens MF, Hickman JA, Langdon SP, Chubb D, Vickers L, Stone R, Baig G, Goddard C, Gibson NW, Slack JA, Newton C, Lunt E, Fizames C, Lavelle F (1987) Antitumor activity and pharmacokinetics in mice of 8-carbamoyl-3-methyl-imidazo[5,1-d]-1,2,3,5-tetrazin-4(3H)-one (CCRG 81045; M \& B 39831), a novel drug with potential as an alternative to dacarbazine. Cancer Res 47: 5846-5852

Stupp R, Hegi ME, Mason WP, van den Bent MJ, Taphoorn MJ, Janzer RC, Ludwin SK, Allgeier A, Fisher B, Belanger K, Hau P, Brandes AA, Gijtenbeek J, Marosi C, Vecht CJ, Mokhtari K, Wesseling P, Villa S, Eisenhauer E, Gorlia T, Weller M, Lacombe D, Cairncross JG, Mirimanoff RO; European Organisation for Research and Treatment of Cancer Brain Tumour and Radiation Oncology Groups (2009) National Cancer Institute of Canada Clinical Trials Group. Effects of radiotherapy with concomitant and adjuvant temozolomide $v s$ radiotherapy alone on survival in glioblastoma in a randomised phase III study: 5-year analysis of the EORTC-NCIC trial. Lancet Oncol 10: 459-466

Stupp R, Mason WP, van den Bent MJ, Weller M, Fisher B, Taphoorn MJ, Belanger K, Brandes AA, Marosi C, Bogdahn U, Curschmann J, Janzer RC, Ludwin SK, Gorlia T, Allgeier A, Lacombe D, Cairncross JG, Eisenhauer E, Mirimanoff RO; European Organisation for Research and Treatment of Cancer Brain Tumor and Radiotherapy Groups; National Cancer Institute of Canada Clinical Trials Group (2005) Radiotherapy plus concomitant and adjuvant temozolomide for glioblastoma. $\mathrm{N} \mathrm{Engl} \mathrm{J}$ Med 352: 987 - 996

Tisdale MJ (1987) Antitumor imidazotetrazines - XV. Role of guanine O6 alkylation in the mechanism of cytotoxicity of imidazotetrazinones. Biochem Pharmacol 36: 457 -462

Van Nifterik KA, van den Berg J, Stalpers LJ, Lafleur MV, Leenstra S, Slotman BJ, Hulsebos TJ, Sminia P (2007) Differential radiosensitizing potential of temozolomide in MGMT promoter methylated glioblastoma multiforme cell lines. Int J Radiat Oncol Biol Phys 69: 1246-1253

Vlassenbroeck I, Califice S, Diserens AC, Migliavacca E, Straub J, Di Stefano I, Moreau F, Hamou MF, Renard I, Delorenzi M, Flamion B, DiGuiseppi J, Bierau K, Hegi ME (2008) Validation of real-time methylation-specific PCR to determine O6-methylguanine-DNA methyltransferase gene promoter methylation in glioma. J Mol Diagn 10: $332-337$

Watts GS, Pieper RO, Costello JF, Peng YM, Dalton WS, Futscher BW (1997) Methylation of discrete regions of the O6-methylguanine DNA methyltransferase (MGMT) CpG island is associated with heterochromatinization of the MGMT transcription start site and silencing of the gene. Mol Cell Biol 17: 5612-5619

Yachi K, Watanabe T, Ohta T, Fukushima T, Yoshino A, Ogino A, Katayama Y, Nagase H (2008) Relevance of MSP assay for the detection of MGMT promoter hypermethylation in glioblastomas. Int J Oncol 33: $469-475$ 